
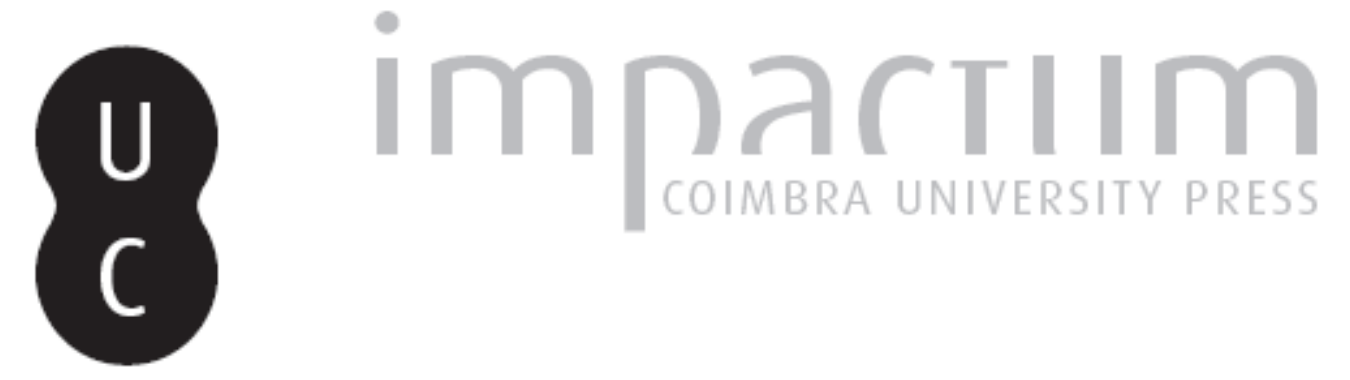

Uma estela epigrafada da Herdade dos Franciscos: (Garvão)

Autor(es): $\quad$ Gomes, Rosa Varela; Gomes, Mário Varela

Publicado por: Imprensa da Universidade de Coimbra

URL persistente:

URI:http://hdl.handle.net/10316.2/45673

DOI:

DOI:https://dx.doi.org/10.14195/1647-8657_23_3

Accessed : $\quad$ 26-Apr-2023 14:32:44

A navegação consulta e descarregamento dos títulos inseridos nas Bibliotecas Digitais UC Digitalis, UC Pombalina e UC Impactum, pressupõem a aceitação plena e sem reservas dos Termos e Condições de Uso destas Bibliotecas Digitais, disponíveis em https://digitalis.uc.pt/pt-pt/termos.

Conforme exposto nos referidos Termos e Condições de Uso, o descarregamento de títulos de acesso restrito requer uma licença válida de autorização devendo o utilizador aceder ao(s) documento(s) a partir de um endereço de IP da instituição detentora da supramencionada licença.

Ao utilizador é apenas permitido o descarregamento para uso pessoal, pelo que o emprego do(s) título(s) descarregado(s) para outro fim, designadamente comercial, carece de autorização do respetivo autor ou editor da obra.

Na medida em que todas as obras da UC Digitalis se encontram protegidas pelo Código do Direito de Autor e Direitos Conexos e demais legislação aplicável, toda a cópia, parcial ou total, deste documento, nos casos em que é legalmente admitida, deverá conter ou fazer-se acompanhar por este aviso.

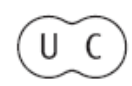


FACULDADE DE LETRAS

INSTITUTO DE ARQUEOLOGIA

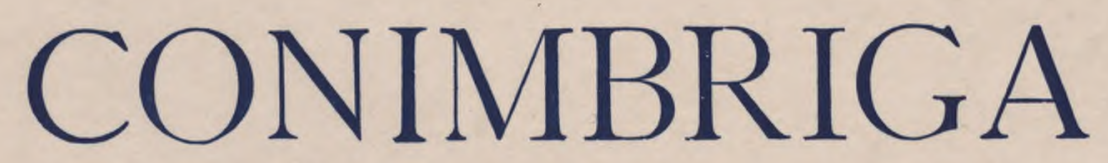

VOLUMEXXIII

UNIVERSIDADE DE COIMBRA

1984 
ROSA VARELA Gomes

Licenciada em Historia

MÁrio VARELa Gomes

Arquitecto

UMA ESTELA EPIGRAFADA DA HERDADE DOS FRANCISCOS

(GARVÃO)

«Conimbriga», XXIII (1984), p. 43-54

Resumo: Os autores estudam a estela erguida à memória de Ladronus, filho de Dovaius, Bracarus do Castello Durbede, falecido com 30 anos de idade, encontrada perto das ruínas de um vicus ou de uma villa rustica, na Herdade dos Franciscos (Garvão) que ofereceu materiais dos sécs. i ao m d.C.

Este monumento, pertencente ao grupo de lápides provenientes do Sudoeste Alentejano (Conventus Pacensis, Lusitania), mostra realização pouco cuidada, com formulário simples, sem a invocação aos deuses Manes, utilizando grande variedade na forma das letras. As suas características permitiram integrá-la num meio pouco erudito e tardo, do séc. $\pi$ ou dos inícios do séc. $m$ d.C.

Os antropónimos registados encontram paralelos, sobretudo, no NO Peninsular, de onde emigram muitos outros galaicos para se instalarem na Lusitânia e na Bética, atraídos pelos trabalhos de mineração ou pela colonização das suas extensas planícies. O Castello Durbede poderá ser algum dos muitos pequenos povoados fortificados da zona de entre Lima e Ave, talvez perto de Ronfe, povoação de onde provém a ara dedicada ao Deus Durbedico (possivelmente uma divindade indígena, aquática e ctónica, protectora da comunidade ali instalada).

RÉSUMÉ: Les auteurs étudient la stèle érigée à la mémoire de Ladronus, fils de Dovaius, Bracarus de Castello Durbede, décédé à l'âge de 30 ans, trouvée près des ruines d'un vicus ou villa rustica, dans 1'Herdade dos Franciscos (Garvão), et où l'on a recueilli des matériaux du I au III siècle ap. J.-C. 
Ce monument qui appartient au groupe des stèles funéraires provenant du Sud-Ouest Alentejan (Conventus Pacensis, Lusitania), révèle une facture peu soignée, avec formulaire simple sans l'invocation aux dieux mânes, utilisant une grande variété dans la forme des lettres.

Ses caractéristiques permettent de l'intégrer dans un milieu peu érudit et tardif, du II siècle ou du début du III siècle ap. J.-C. L'onomastique relevé trouve leurs équivalents, surtout, dans le NO de la Péninsule, d'où émigrent un grand nombre d'autres Callaeci qui viennent s'installer en Lusitanie ou en Bétique, attirés par les travaux d'exploitation minière ou par la colonisation de leurs vastes plaines.

Castello Durbede était probablement une des petites aglomérations fortifiées de la région entre le Lima et l'Ave, située peut-être au voisinage de Ronfe, localité d'où provient l'autel consacré au Deus Durbedicc (sans doute une divinité indigène, aquatique et chtonienne, protectrice de la communauté y installée). 


\section{UMA ESTELA EPIGRAFADA DA HERDADE DOS FRANCISCOS (GARVÃO)}

\section{A descoberta}

No mês de Maio de 1981, dirigimo-nos a Garvão com a finalidade de ali observarmos uma estela epigrafada da I Idade do Ferro, descoberta havia algum tempo e que fazia parte de um pequeno núcleo de objectos arqueológicos, reunidos pelo «Grupo Cultural e Recreativo» local.

Integrada naquela colecção encontrava-se ainda a estela que é objecto desta notícia, recolhida na Herdade dos Franciscos, em Agosto de 1980, pelos senhores J. Pacheco e M. Zacarias, activos membros do grupo referido.

A Herdade dos Franciscos é um dos latifúndios da freguesia de Garvão, situando-se apenas cerca de $1 \mathrm{Km}$ a sul daquela vila. Administrativamente pertence ao concelho de Ourique e ao distrito de Beja (Fig. 1). O monumento funerário agora dado a conhecer foi descoberto avulso, numa extensa zona da herdade onde se observam ruínas, talvez de um vicus, ou de uma villa rustica e de onde provêm outros materiais do período romano.

Caetano Beirão e José Olívio Caeiro procederam ali a escavações de emergência, numa área que iria ser afectada pela construção de uma estrada, identificando-se na altura restos de estruturas habitacionais e materiais romanos que abrangem um período situado entre os séculos i e m d.C. 


\section{0 monumento (Fig. 2 e 3)}

Mostra forma estelar, subparalelepipédica, pouco espessa, aproveitando uma laje natural de xisto grauváquico comum na região, não muito duro, de cor cinzenta, com pátina de cor castanha clara, rudemente afeiçoada, medindo actualmente $0,68 \mathrm{~m} \mathrm{x}$ $\mathrm{x} 0,40 \mathrm{~m}$ e com a espessura máxima de $0,125 \mathrm{~m}$.

A face epigrafada apresenta sinais de regularização encontrando-se mal conservada, com fracturas várias e com uma extensa ferida na parte inferior, provocada pelo ferro de uma charrua, talvez a que pôs a descoberto a lápide.

Longitudinalmente, junto ao bordo direito, uma extensa fractura atingiu o campo epigráfico e amputou o monumento em cerca de $1 / 6$ do que calculamos ter sido o seu volume inicial.

Os restantes bordos da peça mostram ainda algumas fracturas e estalamentos, encontrando-se a parte inferior ou proximal afeiçoada em cunha, de modo a permitir uma melhor fixação ao terreno. A parte enterrada teria uma altura de $0,15 \mathrm{~m}$, ficando a última linha da inscrição perto do solo.

O campo epigráfico, de forma rectangular, actualmente com $0,35 \mathrm{~m} \mathrm{X} 0,30 \mathrm{~m}$ ocupa a parte central da estela, deixando em seu redor um espaço que era constituído por quatro faixas anepígrafas, uma na parte superior e outra na inferior, sensivelmente com as mesmas dimensões $(0,15 \mathrm{~m})$, medindo a faixa lateral do lado esquerdo, cerca de $0,10 \mathrm{~m}$ de largura. A faixa lateral direita desapareceu com a fractura longitudinal que o monumento sofreu.

Seis linhas auxiliares, paralelas entre si e distanciadas de $0,04 \mathrm{~m}$ a $0,06 \mathrm{~m}$, decrescendo as suas larguras de cima para baixo, ordenam o texto no espaço epigráfico, dando-lhe maior marcação e dividindo-o para nele se inscreverem as letras.

A primeira linha auxiliar mostra um esboço finíssimo, realizado anteriormente ao traço profundo que limita superiormente o campo epigráfico, notando-se menor marcação das linhas auxiliares na parte média da inscrição e estando ausente a marcação da última linha. Na gravação da epígrafe foram primeiramente esboçadas, por incisão fina, as linhas auxiliares e as letras, marcando-se em seguida algumas das linhas auxiliares por abrasão, terminando-se 
por aprofundar os traços constituintes das letras, utilizando-se também a abrasão.

Tanto a gravação das letras como das linhas auxiliares apresentam secção em forma de $\mathrm{V}$, mostrando ter sido usada a ponta de um artefacto metálico, possivelmente de ferro.

O texto está mal alinhado à esquerda sendo possível que na parte direita, hoje perdida, face as medidas das letras em falta, encontrássemos situação idêntica.

As letras são capitais, algumas assimétricas, com ductus irregular e hesitações, raramente se sobrepondo às linhas auxiliares. Separando as palavras encontramos, um pouco acima da meia altura das letras, os puncti distinguentes.

A leitura desta epígrafe, com luz rasante, permitindo-nos executar o decalque cuja redução apresentamos na fig. 2, sempre preferível a um desenho, é a seguinte:

\section{LADRONV[S] / DOVAI - BRA[CA]/RVS - CASTEL[LO] / DVRBEDE • [H]IC / SITVS • ES[T] • AN[N]0/RV[M] XXX (triginta ?) / [S(it)]・[T(ibi)]・ T(erra) $\bullet \mathrm{L}(\mathrm{ms}) \bullet$}

A sua tradução parece não nos oferecer grandes problemas propondo-se:

Aqui jaz Ladronus (filho de) Dovaius, Bracarus do Castello Durbede, de trinta anos de idade. Que a terra te seja leve.

As letras mostram alturas muito variáveis conforme podemos observar:

$\begin{array}{cccc}\text { Linha } 1: 1,3 \text { e } 4 & -0,045 \mathrm{~m} & \text { Linha } 2: 1,3 \text { e } 4 & -0,04 \mathrm{~m} \\ 2 & -0,05 \mathrm{~m} & 2 \text { e } 5 & -0,03 \mathrm{~m} \\ 6 \text { e } 7 & -0,04 \mathrm{~m} & 6 & -0,035 \mathrm{~m} \\ 5 & -0,035 \mathrm{~m} & 7 \text { e } 8 & -0,045 \mathrm{~m} \\ \text { Linha } 3: 1,5 \text { e } 6 & -0,04 \mathrm{~m} & \text { Linha } 4: 1,2 \text { e } 5 & -0,035 \mathrm{~m} \\ 2,3,4, & & 3 \text { e } 4 & -0,04 \mathrm{~m} \\ 7 \text { e } 8 & -0,035 \mathrm{~m} & 6 \text { e } 7 & -0,03 \mathrm{~m} \\ 9 & -0,03 \mathrm{~m} & 8 & -0,025 \mathrm{~m}\end{array}$

Conimbriga, 23 (1984), 43-54 


$$
\begin{aligned}
& \text { Linha 5: } 1 \text { e } 6-0,035 \mathrm{~m} \text { Linha 6:2 }-0,035 \mathrm{~m} \\
& 2,3,4, \quad 4,5 \text { e } 6-0,03 \mathrm{~m} \\
& 9 \text { e } 10-0,03 \mathrm{~m} \text { Linha } 7: 3 \text { e } 4 \quad-0,04 \mathrm{~m} \\
& 5-0,05 \mathrm{~m} \\
& 7 \text { e } 8-0,04 \mathrm{~m}
\end{aligned}
$$

Nota-se imediatamente um decréscimo na altura das letras, sobretudo a partir da terceira linha.

A letra $A$ mostra sempre maiores dimensões que as restantes e pelo modo como se encontra grafada quase parece um A. O $N$ apresenta duas formas distintas, lembrando letras idênticas dos alfabetos pré-latinos peninsulares.

As letras $O$ e $I$ têm sempre, numa mesma linha, alturas inferiores às das restantes letras, fazendo também por isso recordar as escritas pré-latinas, onde aliás se faz uso generalizado de linhas auxiliares, constituindo autênticas carteias.

\section{Comentário}

O monumento agora estudado integra-se num grupo de esteias funerárias provenientes do Sudoeste Alentejano (Conventus Pacensis, Lusitania). Esse grupo apresenta como características principais, que o individualizam, em relação à restante epigrafia peninsular, a utilização de lajes de xisto, naturais ou rudemente afeiçoadas, desprovidas de molduras, com o campo epigráfico dividido por linhas auxiliares, utilizando nas letras grande variedade formal, até numa mesma lápide, detectando-se frequentes erros ortográficos, faltas e hesitações, em textos concisos com formulário simples, onde geralmente se não faz a invocação aos deuses Manes.

A análise formal desta esteia permite-nos integrá-la num meio pouco erudito, onde se conhece de modo deficiente o latim e as regras da epigrafia romana, sobretudo as suas fórmulas típicas, revelando inexperiência e, como acima indicámos, aspectos que denotam arcaísmos de que encontramos analogias em formas da epigrafia pré-latina. Este último aspecto não deve ter outro significado que o de simples convergência formal pois não esqueçamos que, no Sudoeste Peninsular, existe um largo hiato, contando mais de cinco séculos, que decorre entre a utilização da escrita na 
I Idade do Ferro e a escrita em caracteres latinos. Esta descontinuidade impede-nos pois de, em termos históricos e culturais, aceitarmos qualquer relação, mesmo técnica, da epigrafia da I Idade do Ferro com a do período romano. Uma hipótese, no entanto ainda em aberto, é a de formas dos alfabetos da área levantina e do Sudeste Peninsular, ali utilizados até à romanização, conhecidos apenas esporadicamente no Sudoeste durante a II Idade do Ferro, como nos mostram os numismas de Kevion (Alcácer do Sal) e um número escasso de grafitos (mesmo alguns desses claramente importados do Sudeste) poderem, de certo modo, ter influenciado aspectos da epigrafia romana daquela área (Beirão e Gomes, 1980; 1982).

O tipo de letras, a sua forma variável, os $A$ com as barras muito descaídas e os $E$ e os $L$ com as barras muito curtas e inclinadas, conduzem-nos a datar este monumento, onde está ausente a invocação aos deuses Manes e com construção epigráfica vulgar, de tipo evolucionado com características tardias, no séc. n d.C. ou mesmo nos inícios do séc. $m$ d.C. As esteias funerárias posteriores ao séc. $m$ d.C. integram geralmente na sua formulação a era hispânica, o que não acontece ainda no monumento agora estudado, permitindo-nos melhor aceitar a cronologia proposta.

Uma barra vertical cortando o primeiro signo do registo da idade do defunto levanta-nos o problema de ficarmos na incerteza se o lapicida quis mencionar trinta anos ou, antes, outra idade próxima daquela, que também por erro não ficou explícita.

Ladronus Bracarus, filho de Dovaius, falecido na Lusitânia aos 30 anos de idade, parece-nos ter sido um indígena romanizado, sendo um dos seus nomes - Bracarus — de clara origem étnica.

O antropónimo Ladronus foi já registado em pelo menos três lápides, provenientes respectivamente de Cárquere (Lamego) (Ladroni) (CIL II, 5248; ILER, 4876), Monte Mosinho (Penafiel) e Alvarelhos (Santo Tirso) (Fig. 1) (Le Roux e Tranoy, 1974, p. 250-252; Silva, 1980, p. 84-85, ests. Ill e V; Vives, 1971, p. 454).

A lápide de Penafiel refere um Ladronus filho de Avitus, também um indígena, devendo ser datada da primeira metade do séc. II d.C. A inscrição de Alvarelhos cita um Ladrono Antonio, filho de Camalus, a quem os madequisenees, habitantes do Castelo da Maia, erigiram aquele monumento, nos meados do séc. $m$ d.C. 
Um antropónimo indígena semelhante - Adronus — foi já detectado, pelo menos duas vezes, em inscrições do Conventus Bracarensis, urna proveniente de Braga (CIL II 2430) e outra do Castro de Rubiás (Orense) (ClL 2519; ILER 2226) (Fig. 1).

Também o patronímico Dovai foi anteriormente registado numa lápide descoberta em Villar del Pedroso (Cáceres) onde é mencionado um Maelo Dovai filius (CIL II 6336; ILER 3817) (Fig. 1).

$\mathrm{Na}$ inscrição dos Franciscos este patronímico aparece em genitivo e não se faz acompanhar da abreviatura $F$., indicativa da filiação, falta que se deve atribuir ao rude conhecimento do latim, também revelado nesta esteia com a ausência de outras letras (o $H$ de hic e um $N$ de annorum) ou a hábitos autóctones de denominação, ainda próprios de populações pouco romanizadas (Faust, 1979, p. 436; Firmat, 1976, p. 62-63). O etnónimo maior Bracarus, aqui na sua forma indígena, foi detectado em inscrições provenientes de Vila Fria (Felgueiras) (ILER 5354) e de Vila da Feira (ILER 943) (Fig. 1) (Firmat, 1975, p. 44). Como a menção do etnónimo maior não fosse julgada suficiente para indicar a origem do indivíduo tumulado, foi ainda registada na lápide de Garvão a sua naturalidade, a procedência real ou origo, juntando-se o etnónimo menor Castello Durbede, situação que encontra vários paralelos. Assim, numa estela de Calañas (Huelva) menciona-se um Limicus do Castello Berensi e, um outro, do Castello Talabrica (Conventus Bracarensis), é referido numa lápide de El Repilado (Huelva), revelando-nos também uma unidade étnica suprafamiliar (Luzón, 1974, p. 290, 295; Firmat, 1975, p. 41, 64, 66).

E portanto normal que ao nome e ao patronímico se juntem uma ou mais entidades suprafamiliares, etnónimos referidos ao populus (raramente), à civitas, à tribo ou ainda à gentilitas a que pertencia o indivíduo tumulado.

Regista-se na esteia agora estudada um topónimo, em ablativo, que corresponde a um povoado fortificado de que ainda não possuímos testemunhos arqueológicos, importando referir que dele pode derivar o teónimo adjectivado Durbedico (dat.), encontrado numa lápide proveniente de Ronfe (Guimarães) (CIL II, 5563; ILER 808). Parece-nos pois estarmos em presença de uma divindade indígena de sexo masculino conforme nos mostra a adopção do sufixo ico 
(Deus Durbedicus), possivelmente protectora do Castello Durbede e da comunidade ali instalada, encontrando paralelo com outros deuses e génios tutelares de povoações ou vinculados aos oppida (Cuevillas e Pinto, 1933-34, p. 353-356; Firmat, 1975, p. 56-60).

A classificação do Deus Durbedicus no grupo das divindades aquáticas necessita de revisão perante a inscrição dos Franciscos, não sendo todavia de excluir a sua relacionação etimológica com o radical durb, tido como de origem celta, encontrado em potamónimos como durio, durbis e durbiae, já apontados por Leite de Vasconcellos (1905, p. 329-331), (Blázquez, 1977, p. 311-312; Cuevillas e Pinto, 1933-34; p. 319; Encarnação, 1975, p. 177-179), curiosamente associado neste monumento ao antropónimo Ladronus que também parece ter a sua origem em hidrónimos como adu ou adro (= corrente de água) (Firmat, 1966, p. 8, 110).

Outra divindade de carácter aquático Tameobrigus, registada numa lápide votiva encontrada perto da confluência do Douro com o Tâmega, está também conectada, não só com um hidrónimo actual (Tâmega), como com o topónimo Tamagani (CIL II, 2477; ILER 1084) de uma lápide de Chaves, certamente designando uma entidade suprafamiliar vinculada a um povoado (Blázquez, 1977, p. 318-319).

Estes teónimos revelando divindades aquáticas e ctónicas indicam-nos interessantes atributos de alguns dos rios do Noroeste, cujas águas parecem ter desempenhado importantes funções, ao mesmo tempo fecundadoras e profiláticas, sobretudo no quadro mitológico pré-romano.

A estela dos Franciscos é, pois, um importante monumento, atribuível ao séc. $\mathrm{n}$ ou aos inícios do séc. $\mathrm{m}$ d.C., cuja forma $\mathrm{e}$ realização se integra, como vimos, no tipo de lápides encontradas no Sudoeste Alentejano (concelhos de Aljustrel, Ourique e Almodovar) (Encarnação, 1978), embora o seu conteúdo mantenha estreitas ligações com a epigrafia do Noroeste, sobretudo no plano onomástico, para o qual encontrámos paralelos maioritariamente no Conventus Bracarensis (Fig. 1).

O Castello Durbede deverá ser algum das muitas dezenas de pequenos povoados fortificados, a maioria romanizados, da zona de entre Douro e Minho ou, mais precisamente, entre o Lima e o Ave, onde se instalavam os Bracari, talvez sobranceiro ao rio Ave, 
em Ronfe, ou perto daquela povoação, de onde provém a ara dedicada ao Deus Durbedicus. Bem perto de Ronfe, sobre a margem direita do rio Ave, encontram-se dois relevos propícios ao assentamento de comunidades da Idade do Ferro, ambos curiosamente cristianizados com capelas, um a cerca de $2 \mathrm{~km}$ a norte, denominado Anjo, e o outro, $3 \mathrm{~km}$ a sudoeste, com o sugestivo topónimo Crasto e em cuja capela é orago Santa Tecla (cf. Carta Militar de Portugal, Antas — V. N. de Famalicão, 84, 1948).

O conhecimento de mais um castellum $(*)$ integrado na estrutura da organização gentílica, em pleno séc. $n$ ou $m$ d.C., vem confirmar a manutenção de um modelo de organização social, administrativa e política que os romanos terão encontrado, e pelo menos mantido em parte, no Noroeste Peninsular, permitindo identificar outros topónimos que até ao momento por apenas serem precedidos da abreviatura $\mathrm{C}$ - ou $* 0$ foram tidos como centúrias, tese que tem vindo últimamente já a ser posta de parte (Firmat, 1975, p. 62).

Ladronus Dovai um Bracarus do Castello Durbede morreu com a idade média de vida do seu tempo, distante da sua terra natal, num vicus em plena Lusitânia, aliás como outros galaicos (limicus, talabrincensis), de que se conhecem as esteias funerárias no Sudoeste (Cáceres, Huelva), para aí deslocados, talvez atraídos pelas actividades mineiras, como mostram os exemplos epigráficos encontrados na região dos rios Tinto e Odiei, em Huelva (Calañas, Rio Tinto, El Repilado, Villanueva de los Castillejos), ou pelas colonizações das extensas planícies do sul da Lusitânia e da Bética (Luzón, 1974, p. 281, 290, 294, 295, 298, 302; Firmat, 1975, p. 63).

Ainda recentemente também M. Manuela A. Dias (1979), num bem fundamentado trabalho, reconheceu a origem norte-peninsular de muitos antropónimos registados em esteias do Conventus Pacensis, encontrando uma possível explicação na emigração com vista aos trabalhos de mineração. Estes movimentos migratórios que fazem instalar populações do norte da Península

(0 Castellum não deve assumir o mesmo significado que castrum, cujos atributos mais importantes serão o seu aspecto urbanístico com vias ortogonais, orientadas segundo os pontos cardeais, a chamada regra da castrametatio, essencialmente utilizada em acampamentos militares. Os castella são de dimensões mais reduzidas, redutos que visavam o controle de uma posição estratégica. 
no Sul e Sudoeste Ibérico, ocupadas tanto na agricultura como na mineração, mostram, em última análise e de modo claro, as diferentes dinâmicas da ocupação territorial da Península, revelando-nos afinal a mesma fraca densidade populacional que ainda hoje conhecemos nas terras do sul, mais avessas à instalação das comunidades humanas *.

\section{BIBLIOGRAFIA}

Beirão G. M. e Gomes M. V. - $1980-$ A I Idade do Ferro no Sul de Portugal - Epigrafia e Cultura, Museu Nacional de Arqueologia e Etnologia, 33 pp., Lisboa.

- 1982 - Grafitos da Idade do Ferro do Centro e Sul de Portugal, «Actas del III Colóquio Sobre Lenguas y Culturas Prerromanas de la Peninsula Ibérica», Salamanca (no prelo).

Blázquez, J. M.-1977 — Imagen y Mito-Estudios sobre religiones mediterraneas e ibéricas, 496 pp., 167 figs., Ediciones Cristandad, Madrid.

Cue villas, F. L. e Pinto, R. de S.-1933-34 - Estudos encol da Edad do Ferro no Noroeste da Península - As tribus e a sua ccstituzón política, «Arquivos do Seminário de Estudos Galegos», n. ${ }^{\circ}$ VI, pp. 261-367.

Dias, M. M. A. - 1979 - A propósito da inscrição B-143 do Museu Regional de Beja, «Conimbriga», Vol. XVIII, pp. 203-226.

Encarnação, J. d'- 1975 - Divindades Indígenas sob o Dominio Romano em Portugal, Subsidios para o seu estudo, 334 pp., 69 figs., Imprensa Nacional — Casa da Moeda, Lisboa.

- 1978 - Estelas Romanas Inéditas do Sudoeste Alentejano, «Conimbriga», Vol. XVII, pp. 41-53.

- 1979 —* Sociedade Romana e Epigrafia, Museu de Arqueologia e Etnologia do Distrito de Setúbal, 75 pp., 15 ests., Setúbal.

-1979 à) - Introdução ao Estudo da Epigrafia Latina, Cadernos de Arqueologia e Arte, n. ${ }^{\circ}$ 1, Institutos de Arqueologia e de História da Arte, Faculdade de Letras de Coimbra, 49 pp., 6 ests., Coimbia.

Faust, M.-1979 — Tradición lingüistica y estrutura social: El caso de las gentilitates, «Actas del II Coloquio sobre Lenguas y Culturas Prerromanas de la Peninsula Ibérica», pp. 435-452, Universidad de Salamanca, Salamanca.

firmat, M. L. A. - 1966 - La Onomástica Personal Primitiva de Hispania Tarraconense $y$ Betica, Theses et Studia Philologica Salamanticensia XIII, 384, pp., 12 mapas, Salamanca.

* Agradecemos ao Dr. José d'Encarnação as correcções introduzidas neste artigo.

Conimbriga, 23 (1984), 43-54 
- 1975 - Organizaciones supr afamiliar es en la Hispania Antigua, «Boletín del Seminario de Estudos de Arte y Arqueologia», Univeisidad de Valladolid, Vol. XL-XLI, pp. 5-66.

- 1976 - La antroponimia prerromana de la Península Ibérica, «Actas del I Coloquio sobre Lenguas y Culturas Prerromanas de la Peninsula Ibérica,» pp. 57-86, Universidad de Salamanca, Salamanca.

Guimarães, O. - Catálogo do Museu Archeologico, «Revista de Guimarães», Vol. XVIII, pp. 38-72.

HÜ B NER, E. - 1869 - Corpus Inscriptionum Latinarum, Vol. II, Berlim.

- 1892 - Supplementum ad Volumen II, Berlim.

Le Roux, P. e Tranoy, A. - 1974 - Contribution à Vétude des Régions Rurales du NO. Hispanique au Haut-Empire: Deux inscriptions de Penafiel, «Actas do III Congresso Nacional de Arqueologia», Vol. I, pp. 249-258, III ests., Porto.

Luzon, J. M.-1974- Antigüedades Romanas en la Provincia de Huelva, «Huelva: Prehistoria y Antigüedad», Editora Nacional, Madrid, pp. 271-320.

Sılva, A. C. F. - 1980 —* Organizações gentilicias entre Lega e Ave, «Portugalia», Nova Série, Vol. I, pp. 79-90, V ests.

— 1982 - Novos dados sobre a organização social castreja, «Portugalia», Nova Série, Vol. II, pp. 83-94, VI ests.

Vasconcellos, J. L. - 1905 - Religiões da Lusitânia, Vol. II, 372 pp., 82 figs., Imprensa Nacional, Lisboa.

- 1910 - Analecta Archaelogica, "O Arqueólogo Português», Vol. XV, pp. 321-328.

Vives, J. - 1971-Inscripciones Latinas de la España Romana, 631 pp., Barcelona. 


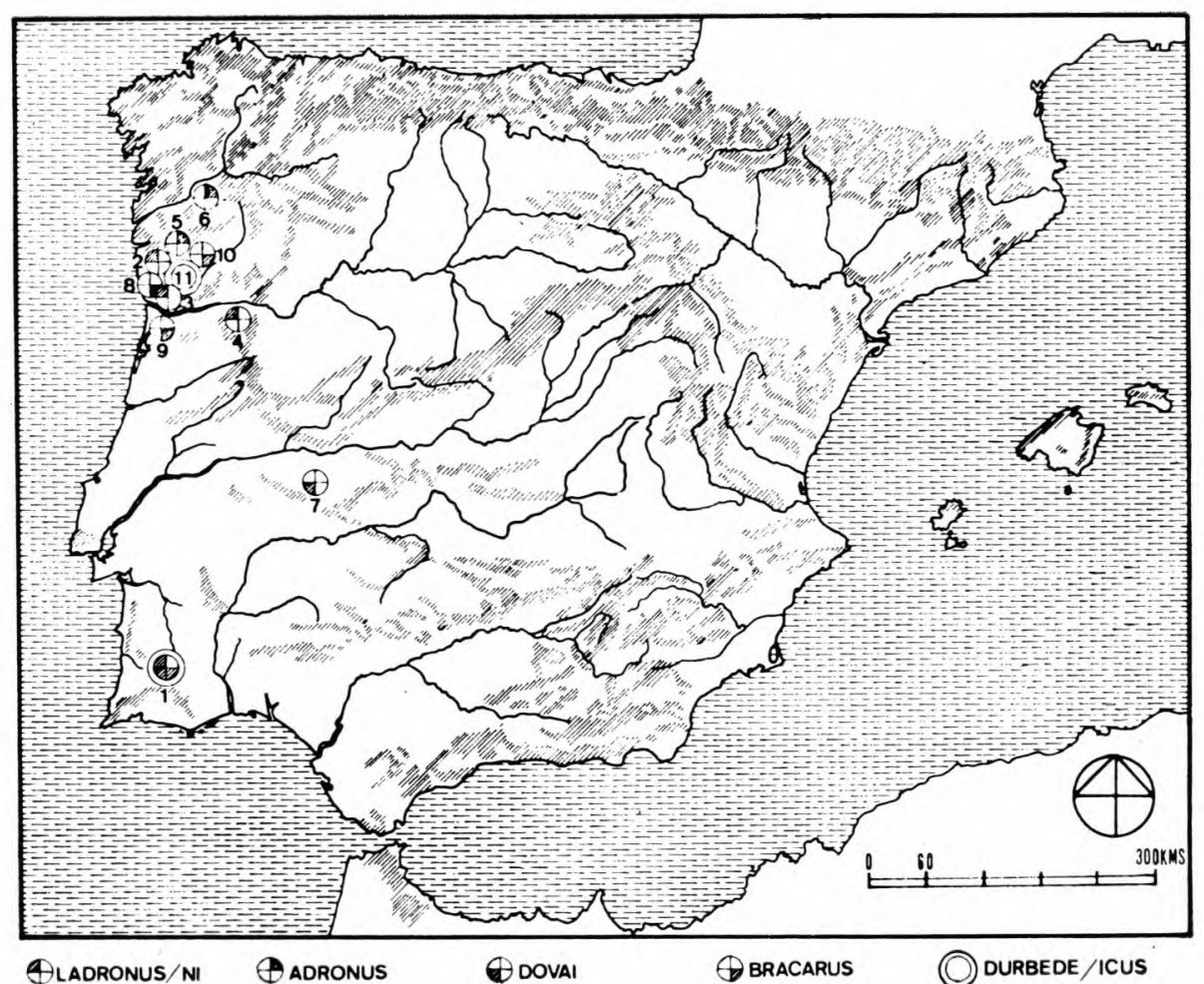

Fig. 1 - Distribuição dos antropónimos encontrados na lápide da Herdade dos Franciscos (a localização é aproximada).

1 - Herdade dos Franciscos (Ourique).

2 - Alvarelhos (Santo Tirso).

3 - Monte Mosinho (Penafiel).

4 - Cárquere (Lamego).

5 - Braga.

6 - Castro de Rubiás (Orense).

7 - Villar del Pedroso (Cáceres).

8 - Vila Fria (Felgueiras).

9 - Vila da Feira.

10 - Braga.

11 - Ronfe (Guimarães). 

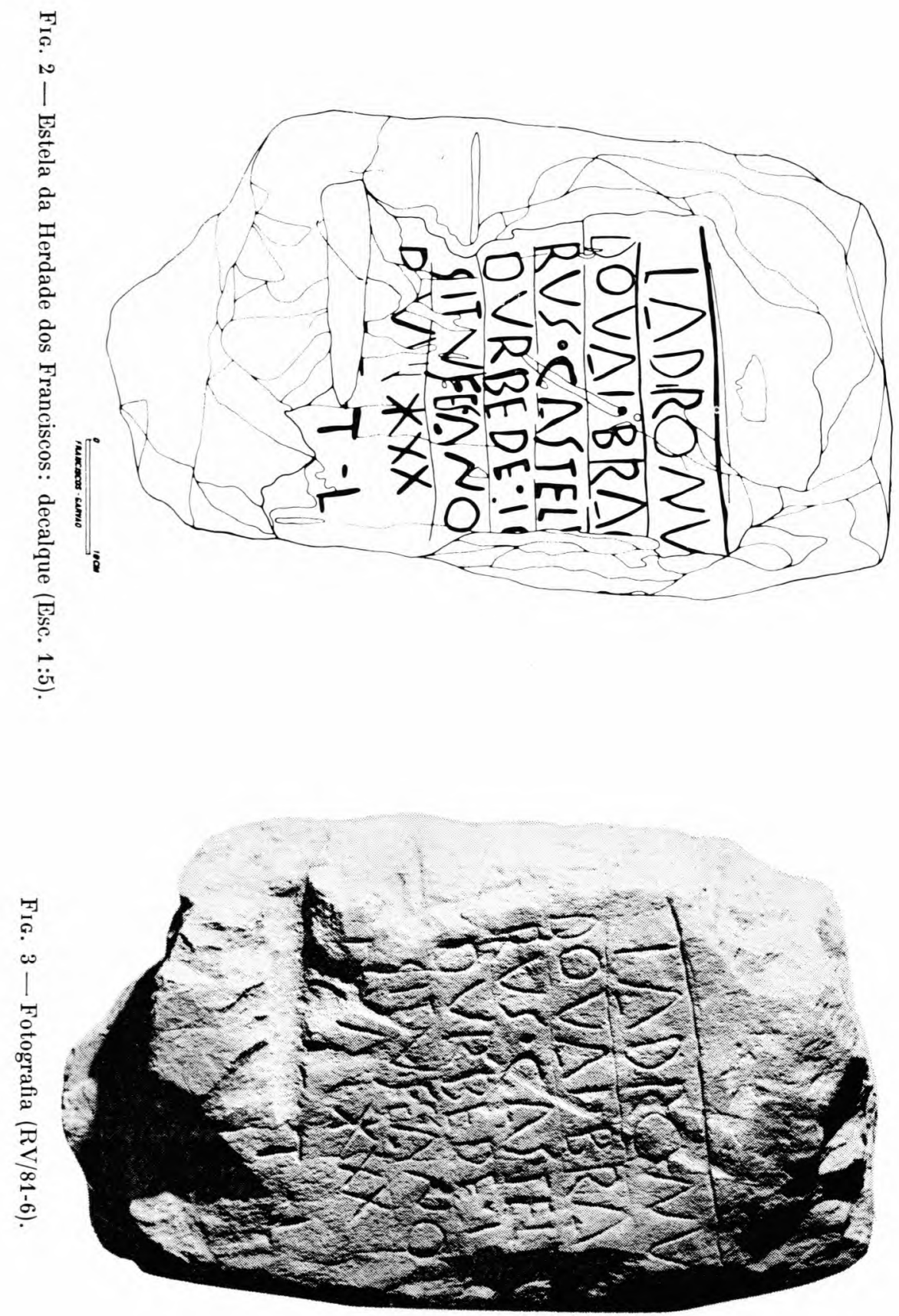